THE EFFECT OF PRIVATE INSURANCE ON

MEASURES OF HEALTH:

EVIDENCE FROM THE HEALTH AND RETIREMENT STUDY

Avi Dor

Joseph J. Sudano

David W. Baker

Working Paper 9774 


\title{
THE EFFECT OF PRIVATE INSURANCE ON \\ MEASURES OF HEALTH: \\ EVIDENCE FROM THE HEALTH AND RETIREMENT STUDY
}

\author{
Avi Dor \\ Joseph J. Sudano \\ David W. Baker \\ Working Paper 9774 \\ http://www.nber.org/papers/w9774 \\ NATIONAL BUREAU OF ECONOMIC RESEARCH \\ 1050 Massachusetts Avenue \\ Cambridge, MA 02138 \\ June 2003
}

The views expressed herein are those of the authors and not necessarily those of the National Bureau of Economic Research.

(C2003 by Avi Dor, Joseph J. Sudano, and David W.Baker. All rights reserved. Short sections of text not to exceed two paragraphs, may be quoted without explicit permission provided that full credit including $($ ) notice, is given to the source. 
The Effect of Private Insurance on Measures of Health:

Evidence From the Health and Retirement Study

Avi Dor, Joseph J. Sudano, and David W. Baker

NBER Working Paper No. 9774

June 2003

JEL No. I11, I18

\begin{abstract}
In this paper we investigate whether the presence of private insurance leads to improved health status. Using the Health and Retirement study we focus on adults in late middle age who are nearing entry into Medicare. Estimation addresses endogeneity of the insurance participation decision in health outcome regressions. Two models are tested, an instrumental variables models, and a model with endogenous treatment effects due to Heckman (1978). Insurance participation and health behaviors enter with a lag to allow their effects to dissipate over time. Separate regressions were run for groupings of chronic conditions. We find that the overall impact of insurance on health tends to be significantly downwards biased if no adjustment for endogeneity is made. With corrections there is a four-fold increase in the insurance effect; yielding a 7 percent increase in the overall health measure for the uninsured. Results are consistent across IV and treatment effects models, and for all major groupings of medical conditions. Thus, the effect of private insurance on health may be larger than previously estimated. As for policy, expanding coverage to the uninsured should result in substantial health improvement. By conjecture, this is likely to reduce the need for health care when individuals retire and enter Medicare, potentially leading to savings.
\end{abstract}

\author{
Avi Dor \\ Department of Economics \\ Weatherhead School of Management \\ Joseph J. Sudano \\ Center for Health Care Research and Policy \\ Case Western Reserve University \\ Department of Medicine \\ Peter B. Lewis Building \\ 11119 Bellflower Rd. \\ Cleveland, Oh 44128-7235 \\ axd9@weatherhead.cwru.edu \\ Case Western Reserve University \\ Rammelkamp 236A \\ 2500 MetroHealth Drive \\ Cleveland, $\mathrm{OH} 44109$ \\ jsudano@metrohealth.org \\ David W. Baker \\ Division of General Internal Medicine \\ Feinberg School of Medicine of Northwestern University \\ 676 N St. Clair St \\ Suite 200 \\ Chicago, IL 60611 \\ dwbaker@northwestern.edu
}




\section{Background}

According to the 2000 U.S. Census, approximately 40 million Americans are uninsured and this number is expected to grow in coming years. Although the Clinton administration was forced to retreat from some ambitious goals for expanding coverage, providing access to the insured is emerging again as major public policy issue. (Winslow and McGinley, 2000). Health benefits in the U.S. remain heavily employer-based with about 60 percent of all insured individuals being enrolled through employer-sponsored plans. (Acs et al., 1996). While the indigent can often qualify for public assistance programs such as Medicaid, many participants in the labor force may not have adequate access to coverage through their employer. Although it is possible to purchase individual plans privately, these may only be available at prohibitively high rates compared with the group rates available through large employers. As a consequence, $16 \%$ of full time workers are uninsured (Custer and Ketche 2000).

Not surprisingly, much of the policy discussion focuses on ways of expanding coverage to all workers. Two competing approaches have been offered. One approach favors expanding employer-based coverage and making it easier for firms to purchase insurance for their employees (Gruber, 2001). Another approach favors providing stronger incentives for purchasing insurance directly to employees. A prime example of the former was the Clinton health care reform plan, which would have allowed small firms to purchase health care insurance at competitive group rates through large purchasing cooperatives (Cutler, 1994). Recently, the Bush administration proposed a tax credit of up to $\$ 1,000$ to help low income workers purchase insurance for their families (Gleckman, 2002). Several other proposals would go further in severing the link between 
employment and health insurance but move towards mandated universal coverage (Blendon, Young, DeRoches, 1999).

Both sides of the debate seem to implicitly be making the assumption that expanding coverage will lead to gains in social welfare. This can occur in two ways: first, by reducing uncertainty for workers and their families, and second, by improving access to medical services and thereby improving health outcomes. Our primary interest is in the latter question, i.e. in determining the impact of insurance on overall health.

Recent studies have tended to focus on mortality, rather than health per se, finding that adults without health insurance have higher mortality than individuals with private insurance (Franks, Clancy, and Gold, 1993; Sorlie et al. 1994). Looking at similar populations, other studies focused on the effect of lack of private insurance on health measures such as physical limitations (Baker et al., 2001, Ross and Mirowsky, 2000). In all of these studies the insurance effects were either small or insignificant. However, none of these studies addressed one important estimation issue, namely endogeneity of the insurance choice variable in the health equation. This potential bias arises if healthier people exhibit behaviors that will make them more (or less) likely to purchase insurance (Gruber et al., 2000). The only study to address this issue explicitly addressed is limited to a specific population, that of HIV-positive individuals (Goldman et al., 2001). That study demonstrated that accounting for the endogeneity in insurance results in a dramatic and statistically significant increase in the effect of insurance on declines in mortality probabilities.

In this study we study we reexamine the endogeneity in a different context. We employ the same sample of middle-aged labor force participants in the Health and Retirement Survey used recently by Baker et al. (2001), but we use a broader measure of 
individual health status. We address the endogeneity issue in the context of a treatment effects model. Our results confirm the direction of the effects found in Baker et al., namely that having insurance leads to better health status. However, we also found that failure to account for endogeneity bias results in underestimating the full effect of insurance. In this respect our results are also in agreement with Goldman et al. (2001.)

The fundamental question we aim to address is as follows: will improved access to private health insurance in and of itself lead to better health outcomes? Evidence to this effect may provide further support in favor of policies designed to expand health insurance coverage, irrespective of the policy mechanism ultimately chosen. The plan of the paper is as follows: Section 2 summarizes the relevant literature on the measurement and determination of health, as well as insurance choice. Section 3 presents the methodological approach and estimation framework. Section 4 presents data and variable definitions. Section 5 presents results from the insurance participation equation and the health status equation for the full sample. In addition it summarizes results from a number of tests for endogeneity bias, along with the magnitude of the bias. Section 6 replicates this analysis for subsets of survey respondents based on groupings of chronic conditions. This was done in order to test whether insurance effects are repeated across various settings in which symptoms of the underlying medical condition may not be equally observable to the individual. Finally, implications of the results are discussed in Section 7.

\section{Previous Literature}

A number of separate themes in the literature are relevant to this study. Among these are the use of physical health measures derived from household surveys; effect of 
insurance on health, including the endogeneity bias that arises in estimation; the relative importance of the effects of health behaviors and insurance on health; and the probability of having insurance. We briefly review each one of them, and explain how they are connected in relation to the research question in this paper.

\section{Health measures:}

There is a substantial body of literature on using survey-based measures of health status. These measures appear with similar wording in major household surveys such as the Medical Expenditures Panel Survey (MEPS), the Health and Retirement Survey, and the National Health Interview Survey. Indicators are generally classified into three types: Subjective measure, i.e. self rated overall health (poor, fair, good, very, excellent), objective measures based on a general criterion, especially physical limitation, defined as inability to perform certain tasks defined in the survey, and objective measures that pertain to self-reporting of specific diagnoses or medical conditions. In general, these measures have been shown to perform well. Perry and Rosen (2001) find that "objective measures give exactly the same answer as subjective measures" (p.19) when testing for differences in health status between wage earners and the self employed. Specifically in the Health and Retirement Study, Hurd and McGarry (1995) find that subjective probabilities of survival vary with health predictors in the same way as actual outcomes.

By combining the variety of self-reported conditions into a single index the Medical Outcomes Study produced a health status measure that minimizes individual error (Ware and Sherborn, 1992, Ware et al., 1995). The index, known as the Short-Form 36 (SF-36), utilizes the same indicators of physical health as those found in large household surveys. The index avoids the use of self-reports on specific diagnoses, which have been shown to be sensitive to false negative errors in Canadian data (Baker, Stabile, 
and Deri, 2001). Variables in the Health and Retirement Study render themselves to a very close approximation of the SF-36 (Baker et al., 2001, 2000), since it includes the same basic groupings of health indicators. Differences are found in the wording used to describe certain physical limitations or conditions. In section 4 we provide further detail regarding construction of this variable in the HRS

\section{Effect of insurance on health:}

A number of recent studies have attempted to estimate the effect of insurance on health, but the results appear to be inconclusive. For working age adults, people without health insurance tend to have higher mortality probabilities than individuals with private insurance (Franks, Clancy, and Gold, 1993; Sorlie et al., 1994). Smaller effects were found for populations with particular diagnoses such as breast cancer in women (Ayanian et al., 1993). In at least one population, that of HIV-positive individuals, the effect of insurance on mortality probabilities turns out to be substantially larger after accounting for endogeneity of insurance in the mortality equation. However, in the case of public insurance programs such as Medicare or Medicaid, only weak effects of insurance on adult mortality or infant mortality were found (Sorlie et al., 1994; Kaestner, Joyce, and Racine, 1999).

Other related studies focused on health status, rather than mortality, as measured by self reported health, physical limitations, and presence of selected medical conditions. Ross and Mirowski (2000) find no significant effects of private or public health insurance on health outcomes. Perry and Rosen attempt to measure insurance effects by comparing two populations with different levels of coverage, namely wage earners and the selfemployed. They conclude that the relative lack of insurance among the self-employed has little to no impact on their health as measured by the presence of medical conditions. On 
the other hand, Baker et al. (2001) finds small but positive and significant effects of private insurance on self-reported health and physical functioning for working age adults, after allowing for appropriate lags. Again, the endogeneity issue was not explicitly addressed in any of these studies.

$\underline{\text { Relative effects of health behaviors and insurance on health: }}$

A more 'established' strain in the literature focuses on the role of human capital. The Grossman model (1972a, 1972b) defined a health production function, in which investments in health care including medical care and home activities exhibit diminishing marginal productivity in maintaining health. The Grossman model also predicts that education increases the efficiency of investment (MEI) across the board, i.e. it shifts the MEI schedule to right. In a study based on the National Health Interview Survey, Kenkel (1991) finds evidence to support this, showing a positive correlation between schooling and health augmenting behaviors. It has been suggested that health behaviors may ultimately be more important than the purchase of medical services (Fuchs, 1998).

\section{'Offer' versus 'take up' decisions:}

More recent research has focus on the likelihood of the firm offering insurance to its employees, namely the offer probability of insurance. An extensive summary of results can be found in Gruber 2001, who emphasizes the importance of tax rates on the offer probability, with elasticities ranging from -0.1 to -0.6 . Bundorff (2002) examined the effect of employee preference and worker characteristics on the offer probability, and found only small effects. Using data centered on firms that provide insurance coverage Chernew, Frick and McLaughlin (1997) show that employees take up probabilities are sensitive to premium levels. Generally, take up probabilities are conditional on the employer actually offering insurance. However, surveys of households and workers tend 
to provide limited information on employers, leading to studies that incorporate individual characteristics, while necessarily omitting firm-level variables (e.g., Simon, 2001).

\section{Methodological Approach}

Addressing the endogeneity issue requires creating an instrument for insurance participation in the health status equation. To meet identification requirements Goldman et al. used state-level policy variables as predictors of insurance, noting that these variables would be correlated with insurance availability via Medicaid for AIDS patients while being uncorrelated with health. Unfortunately, the Health and Retirement Study does not provide any geographic information, including state of residence in the U.S due to strict confidentiality requirements. However, given our focus on private insurance markets, we are aided by the notion the worker's decision to take up insurance is conditional on the employer's offer. Thus the identification problem becomes one of finding instrumental variables that predict the likelihood that an employer offers insurance without being correlated with health status. As we explain later we use a series of Wald-tests to make sure that our instruments are valid. We are also aided by the fact that following Baker et al. (2001) insurance participation enters the health equation with a lag, although this provides a weaker source of identification.

We estimate the following system of equations:

$$
\begin{aligned}
& H_{t}=H\left(X_{t-k}, B_{t-k}, I_{t-k}, H_{t-k}\right) \\
& I_{t-k}=I\left(X_{t-k}, F_{t-k}\right) .
\end{aligned}
$$

Where $\mathrm{H}=$ health index in period $\mathrm{t}, \mathrm{X}=$ socioeconomic characteristics, $\mathrm{B}=$ health indicators and behavioral variables. $\mathrm{I}=$ binary indicator of insurance, and $\mathrm{F}=$ firm or job 
characteristics that predict the likelihood of insurance being offered. Finally k denotes the length of the lag. Equation [1] defines the health "production function" (Grossman, 1972, 1976), while Equation [2] is used to predict the likelihood of having insurance. Equation [2] is the indicator function for purchasing insurance, which can be estimated as a probabilistic model. The decision to purchase insurance is an individual decision, but is conditioned on the employer offering insurance. Most household surveys, including the HRS, do not contain variables that provide this information directly. However, other characteristics of the firm and certain job characteristics serve as indicators of the propensity of the firm to offer insurance benefits. These characteristics are contained in the vector $\mathrm{F}_{\mathrm{t}-\mathrm{k}}$. While interesting issues arise in conjunction with the insurance decision, our main interest in creating a well-identified instrument. Thus the specification of the probability equation is incidental to our main research question.

The lag structure is used in equation [1] to allow for the fact that adjustment to behavioral covariates does not occur instantaneously. For instance, smoking and alcohol abuse require some passage of time before causing adverse health effects ${ }^{1}$. The same can be assumed for health insurance. Including the lagged dependent variable, $\mathrm{H}_{\mathrm{t}-\mathrm{k}}$, is consistent with the Grossman investment model, which states that current health depends on the initial level of health. For convenience, the lag is also applied to time invariant demographic characteristics such as gender, race, and marital status.

\footnotetext{
${ }^{1}$ Lags considered in related seminal medical studies on the effects of smoking, physical activity and alcohol consumption drinking range from one year to a decade, e.g. Frank et al., 1966; LaCroix et al., 1991; Thun et al., 1997.
} 
Although this model can be rewritten in the form of a change equation, ${ }^{2}$ in our particular case we will stop short of interpreting it as such due to a definitional change between in health variables that occurred between the 1992 and 1996 waves of the HRS. In 1996 HRS introduced a change in the phrasing of responses to a small subset of questions that make up the indicators of the health index. This caused a slight upward "creep" in the index. As a result, for some observations health status would appear to artificially increase over time. However, this does not affect the distribution of health status within each wave. Thus the 1992 index provides a reasonable baseline measure of health status, with slightly altered scaling. Note that we are not interested in the magnitude of change in health status per se, but rather in the effect of insurance participation, holding everything else constant. More detail on the construction of the health index is provided in Section 4.

Lagging the effects of health inputs and insurance gives the empirical model its recursive structure. Nevertheless, the two equations may not be independent and the error terms associated with equation [1] and [2] may be correlated if there is some unobserved trait that makes people who purchase insurance more or less likely to be healthy in a future period. For instance, if insurance is positively correlated with an unobserved trait, say 'awareness' and this trait also leads a person to take better care of his health, then the error terms would be positively correlated. In this case the coefficient of insurance in the

2 To this, we first write the health equation in the following form:

$$
\mathrm{H}_{\mathrm{t}}=\mathrm{b}_{0}+\mathrm{b}_{1} \mathrm{Y}_{\mathrm{t}-\mathrm{k}}+(1-\delta) \mathrm{H}_{\mathrm{t}-\mathrm{k}} \text {, }
$$

Where $\mathrm{Y}$ is a vector of insurance and other variables related to health behaviors, and $\delta$ is the rate of depreciation of health stock. Rewriting we get:

$$
\mathrm{H}_{\mathrm{t}}-\mathrm{H}_{\mathrm{t}-\mathrm{k}},=\mathrm{b}_{0}+\mathrm{b}_{1} \mathrm{Y}_{\mathrm{t}-\mathrm{k}}-\delta \mathrm{H}_{\mathrm{t}-\mathrm{k}} \text {, where } \delta \geq 0 \text {. }
$$

The coefficients can be alternatively interpreted as being generated by distributed lag, adaptive expectations, or partial adjustment processes (Maddala, 1980), but these are difficult to distinguish and not rele vant to our discussion. 
health equation would be upward biased. If, on the other hand, insurance is positively correlated with an unobserved trait that also causes a person to neglect her health, e.g., reduce preventive effort, than error terms would be negatively correlated and the coefficient of insurance in the health equation would be downward biased. The final direction of the simultaneity bias cannot be ascertained a priori.

To address this issue, we use a two-step procedure, whereby we initially estimate equation 2 to obtain the predicted value of $\mathrm{I}_{\mathrm{t}-\mathrm{k}}$, or some related transformation (see below) and then substitute this predicted value, or some related transformation (see discussion below) into Equation [1]. Note that the model is statistically identified since the vector of coefficients $\mathrm{F}_{\mathrm{t}-\mathrm{k}}$ is included in [2] but omitted from [1]. The estimation procedure we use is essentially an OLS regression for Equation [2] augmented by the hazard function from a probit regression for [1], i.e., the 'treatment effects' model, due to Heckman (1978, 1979) and Maddala 1983. This model, often referred to as the restricted control function (RCF) method, is appropriate when the censoring of the non-participating group does not take place as it would in the standard Heckman selection model. Moreover it is at least as efficient as its alternative, the instrumental variable estimator (Vella and Verbeek, 1999). The model can be summarized as follows:

$$
H_{i}=\alpha+b I_{i}+\gamma Y_{i}+\sigma_{t \varepsilon} \lambda_{i}+v_{i}
$$

Where $H_{i}$ is health status or some other outcome measure such as expenditures for individual $i, I_{i}$ is a binary indicator of being in the treatment group (in our case, $=1$ if insured, $=0$ if uninsured), $Y_{i}$ is the vector of covariates, $\lambda_{i}$ is the hazard rate obtained from the first stage probit on the treatment indicator (e.g., if individual is insured), and $\sigma_{t e}$ is the covariance of the disturbance terms in the treatment function and the non- 
augmented OLS equation. An algorithm by Maddala (1983, p. 122) provides adjusted standard errors. The estimate of $\sigma_{t e}$ provides a specification test for [3], with high statistical significance indicating that the null hypothesis (the non-augmented OLS equation is true), should be rejected. ${ }^{3}$

RCF is appropriate when the distribution of the dependent variable is fully observed, but assignment to treatment groups is non-random. Unlike the standard Heckman selectivity bias model, where the hazard enters in lieu of the treatment indicator, the RCF method includes the binary indicator in addition to the hazard rate. Thus, RCF allows for direct comparisons of $\alpha$ with the coefficient of the treatment indicator in a simple OLS model. Note that model [3] is very similar to a class of instrumental variable (IV) estimators in which the residuals from a linear probability regression on the indicator function are included in second stage equation in lieu of the hazard rate. ${ }^{4}$

Choosing one model over the other entails a tradeoff between making distributional assumptions about the errors and attaining consistency of the structural parameters of interest. The RCF assumes a bivariate normal distribution of the errors in the first and second stage equation, but yields consistent and efficient structural

\footnotetext{
${ }^{3}$ Stated differently a high correlation between regression errors indicates that endogeneity is present. The covariance term can be expressed in terms of the correlation: $\sigma_{t e}=? \sigma_{e}$. All relevant terms are reported in the regression tables.

${ }^{4}$ The use of residuals to account for endogeneity is commonly encountered in models with censored endogenous regressors. For example, Heckman $(1978,1979)$ adopted this approach to account for sample-selection bias and endogeneity bias in models in which the treatment is captured through an indicator function. Vella (1993) employed the same approach for a range of models involving selection bias or censored endogenous regressors. Smith and Blundell (1986) and Rivers and Vuong (1988) adopted the same idea in accounting for endogeneity in models where the dependent variable is censored and the endogenous regressor is continuous. However corrections for standard errors have not been fully resolved.
} 
parameters. In comparison, the IV model is free of distributional assumptions, but the estimates may be inconsistent. Vella and Verbreek (1999) show that if the normality assumption is satisfied, IV and RCF are identical, and they recommend comparing estimates from both models. Our own comparison (e.g., Table 3) indicated that the two models yielded virtually identical estimates. We opted to present regression results from $\mathrm{RCF}$ since it allows for a more intuitive interpretation of the participation parameter as a 'treatment' or intervention and because it provided corrected standard errors. Henceforth we refer to this model as the 'treatment' model.

\section{$\underline{\text { Identification Strategy }}$}

When selecting instrumental variables, we are aided by the notion that the employee's decision to purchase insurance, i.e., his take-up probability, is conditioned on the employer's offer. In many large household surveys a binary indicator of the firm's offer is not typically available. However, many other employer characteristics may be reported, and can be taken as 'indicators' of the propensity of the employer to provide insurance. In turn, this is substituted into Equation [2] to yield a predictive equation. Similarly, certain job characteristics such as union membership, for instance, may predict access to insurance coverage. Regional indicators may proxy for policies that impact insurance availability (States are intentionally omitted from the Health and retirement Study). Modeling the decision-making process in this simple way provides the necessary motivation for picking appropriate instrumental variables. However, as in all simultaneous equation estimators two important statistical issues need to be addressed. First, a number of studies have cautioned against using poorly fitted predictive models in the first-stage, as they may introduce measurement error that outweighs the benefit from reducing the error due to simultaneous equation bias (e.g., Bound, Jaeger, Baker, 1995; 
Staiger and Stock, 1999). Even when model specification is guided by economic theory, a good fit is not guaranteed. Second, instrumental variables might themselves be correlated with unobservable determinants of outcome in the second stage.

Define Equation [2] as the "insurance participation" equation, with the indicator variable coded as $=1$ if the individual has insurance and $=0$ if the individual does not have insurance, to be estimated as a probit. To address the first concern, we report goodness of fit measures, which are relatively high. We further performed Wald tests for the joint significance of our instruments and find that it is also high. Note that our interest is only in obtaining an instrument for the insurance decision in the second stage health status with variables available in the Health and Retirement Study. ${ }^{5}$

Consider the instruments we picked for the insurance participation equation. We also included employer characteristics such as firm size and a dummy variable indicating if the firm offers a pension plan. The pension plan indicator is a potentially powerful instrumental variable, since it is known to correlate highly with other employee benefits, but there is no reason to assume that it is correlated with employee health. Still, we cannot be completely sure.

Firm size is related to insurance coverage since large firms are better able to pool risks and negotiate lower premiums, but they may also attract healthier workers. We included job characteristics such as union membership and managerial and professional position that imply better access to insurance, but admittedly may also draw healthier

\footnotetext{
${ }^{5}$ Unfortunately, the Health and Retirement Study does not include information on insurance premiums, Cutler (2002) and Dana et al. (2001) propose using state level variables such as marginal tax rates and policy dummies, respectively, which may be uncorrelated with health but correlated with insurance participation. These could not be linked to our file, since states are intentionally omitted in that survey.
} 
workers. It is possible that for the relatively older age group in question, employer and job characteristics have been predetermined, given that job switching for this group is a relatively rare phenomenon.

The hypothesis that an instrumental variable is uncorrelated with unobservable characteristics, and hence with the outcome measure itself, cannot be tested directly. To determine this it is only possible to perform a 'weak test' - by regressing the full set of variables including the proposed instrumental variables on outcomes in second stage (Goldman et al., 2001). As we later explain [section 5] this approach provided us with greater confidence that our assumptions are appropriate, at least for our sample of relatively older adults. We further report Wald tests for joint significance of instrumental variables in the insurance participation probits. While interesting issues arise in conjunction with the insurance decision itself, the results are incidental to our main research question. Our interest here is limited to creating a well-identified instrument in the health status IV and treatment effects models. These and other variables are discussed below.

\section{Data and Variables.}

Our data came from the Health and Retirement Study, which is a household survey of mostly working age adults. As part of this survey, follow-up interviews were conducted every two years. For purposes of our research we focused on wave 1 and wave 3, corresponding to the years 1992 and 1996. In 1992, face-to-face interviews were conducted for 7702 households, yielding a total of 12,652 individuals for wave 1 (1992). We focused our sample on adults 45-64 years old; few people below age 45 participated, and almost all participants age 65 and older at baseline were insured through Medicare. 
Because we were interested in the insurance choices available to participants in the labor force, we also excluded a small number of Medicaid and Medicare beneficiaries, and those enrolled through other Federal health insurance programs(e.g., Veteran's Administration, CHAMPUS). Due to the lagged variable structure of our estimation procedure, we further considered only individuals who participated in both waves. This and a small number of omitted observations due to missing data resulted in a final sample size of 9,050 individuals.

Our main dependent variable is the health index wave 3 , which is a summary measure of self-reported overall health, two measures of physical limitations (mobility and agility), and a measure of pain. All four components of this health index are coded so that higher values indicate better health. ${ }^{6}$ The same structure is used to generate an independent health index wave 1, which provides a measure of baseline health status. The health index used in our analysis closely mirrors the construction of a widely used summary measure of physical health known as the SF-36. Examples of recent studies in the health care literature that have used variants of this measure in empirical work include Baker et al. (2001), Ware (2000), Mirowsky and Ross (1998). Indeed, regression analysis

\footnotetext{
6 The component items of the index are as follows: Self-reported overall health, with the options excellent, very good, good, fair, or poor (coded $5=$ excellent to $1=$ poor). The physical mobility component which measures ability to perform activities requiring large muscle strength using 4 items: walking several blocks; walking one block; climbing several flights of stairs; climbing one flight of stairs without resting. The agility component measures physical activities required to perform instrumental activities of daily living using 6 items: sitting for about 2 hours; getting up from a chair after sitting for long periods; lifting weights over 10 pounds; stooping, kneeling or crouching; pulling/pushing a large object; and reaching/extending arms above shoulder level. Items were coded 1 if the respondent reported no difficulty with the activity, 0 otherwise, then summed for each component. The pain level measure is taken from several items in the questionnaire that ask respondents to characterize their pain as none, very mild, mild, moderate, and severe (coded from 5 to 1 , respectively). Finally, all 4 measures were summed and scaled to form the 100-point health index. A test of the correlation of rankings across the various items indicated a very high degree of internal consistency (Cronbach's alpha $=0.82$ ).
} 
on this index yields results that are consistent with some well known biological and behavioral phenomena (see section 5).

All independent variables in the health equation were taken from wave 1, i.e. as lagged values. This included socioeconomic variables age, gender, race, marital status, years of school completed, and household income (measured as the ratio of total household income to the official U.S. poverty line in 1991, adjusted for family size). In addition, they include variables that reflect past health behaviors, such as smoking, number of alcoholic drinks of per day, and measures of initial health stock such as the body-mass index (weight in kilograms divided by height in meters squared), the number of chronic conditions reported in HRS (including hypertension, diabetes, heart disease, chronic lung disease, cancer, arthritis, stroke, and visual difficulties), and finally the lagged health index. Not shown in the Table 1 are the ranges of the body-mass index: quintile 1: 16.7 - 23.0; quintile $2: 23.0$ - 25.2; quintile $3: 25.3-27.4$; quintile $4: 27.4$ 30.5; quintile 5: 30.6-50.5. According to actuarial and epidemiological standards, persons are considered "overweight" if their BMI is between 25 and 30, and 'obese' if BMI > 30. Thus the third and fourth quintiles correspond to the overweight category, and the fifth quintile corresponds to the obesity category (see Averett and Korenman, 1996, for instance).

Between the 1992 and 1996 surveys, there was a change in wording of questions and response options for items in the physical difficulties subscale ${ }^{7}$. Health is expected to

\footnotetext{
${ }^{7}$ In 1992 the options for the physical difficulties in the HRS were 'not at all difficult' 'a little difficult', 'somewhat difficult', and 'very difficult/cannot do'. In 1996 the question was rephrased to 'Do you have any difficulty?' with the responses: no; yes; cannot do. To have consistency between the questions and response options in 1992 and 1996, we used a similar approach to that used in previous studies. (Baker et al., 2001; Clark, et al. 1998, Burchett et al., 1993): all questions for 1992 and 1996 were dichotomized into no difficulty $(=0)$ versus some difficulty (=
} 
decline with time; thus the small increase in mean health index from 75.8 to 77 reported in Table 1 is probably an artifact of a slight change in scaling rather than a reflection of a true increase in health status. However, the distributions are similar in both waves, suggesting that the 1992 index provides a reasonable measure of baseline health. As can be seen from Appendix A, the moments of the distribution for both the insured and uninsured are virtually equal for both periods.

The main variable of interest is insurance participation. Survey respondents were classified as insured regardless of whether they had employer-based or individual policies. In the full sample there were 7,507 individuals with any insurance policy of which 1,543 were uninsured. ${ }^{8}$ The Health and Retirement Survey does not contain a variable indicating whether the employer actually offered health insurance to employees. However, several indicators for the firm's propensity to offer such insurance are available. Among these are employer size, availability of other employer sponsored benefits such as a 401k plan (pension), and an indicator of the worker's ability to get insurance through other sources, e.g. union membership. In addition, we include a binary indicator of job characteristics ( $=1$ if professional or managerial), to account for firms that limit health benefits to certain classes of employees. We also included a binary indicator of employment (6,601 individuals were on-the-job at the time of the survey). Thus, job and employer characteristics in the model are effectively interaction terms.

1). The absence of the option 'a little difficult' in 1996 may have prompted certain respondents to report 'no difficulty', for instance.

${ }^{8}$ Individuals who said they had only minimal coverage, e.g. coverage for special conditions such as mental health, dental insurance, or long-term care insurance were classified as uninsured because these policies do not enable access to routine health care services. In the full sample, there were only 360 such cases. 
Regional variables were also included in the regression, to account for differences in mandates and premium regulation, which vary from state to state, but are known to exhibit regional patterns. Detailed definitions and summary statistics are presented in Table 1. Summary statistics for binary indicator are the percent in the sample belonging to group. Means and standard deviations are reported for continuous variables. Results from the first stage regressions on insurance participation, and second stage regressions on health status are described below.

Other regressions replicated the analysis by type of major chronic condition available in the Health and Retirement Survey. We designate these as follows: Population 1 , persons with no major chronic condition at all; Population 2, persons with any major medical conditions, i.e. heart disease, stroke, cancer, arthritis, asthma or other chronic lung disease, diabetes, and hypertension; Population 3, the subset of persons with asymptomatic conditions, i.e., conditions which may not have external symptoms in early stages of the disease, namely hypertension and diabetes; and finally, population 4 , persons with hypertension, the single most common chronic condition in the population. Note that populations 2-4 are nested; population 4 is a subgroup of population 3 , and population 3 is a subgroup of population 2. In addition, this list of medical conditions is by no means exhaustive; other medical conditions that may be prevalent in the population are simply not reported for respondents in the survey. Sample sizes for our grouping were $3210,5,640,3,598$, and 3290 respectively. Further detail of definitions of medical conditions are reserved for Section 6. 


\section{Results: The Full Sample}

$\underline{\text { First-stage estimates: probability of insurance participation }}$

Table 2 presents probit estimates on insurance participation. Two versions of the model are shown. The only explanatory variables included in Model 1 are predictors of the 'offer' probability for insurance. Model 2 adds socioeconomic characteristics that are related the take-up decision. Thus this model has the interpretation of a 'take-up' probability, conditional on being offered insurance by the employer. In either case are not interested in the insurance participation decision per se. Rather, we aim to create an instrument that can be incorporated into the second stage estimates of health status in either an IV or treatments effects setting. The two models we employ corresponds to two levels of identification: First, an instrument that meets identification criteria, but is more parsimonious; second a model that adds regressors from the second stage that have a theoretical meaning in the insurance decision, but are not strictly required for identification purposes. The choice of the two models entails a tradeoff in terms of our identification strategy. The first model might allow a higher correlation of the instruments with treatment variable. The second model should allow for a better overall fit of the predictive model and is akin to a 2SLS procedure. To help choose the better model we report the usual goodness of fit statistics for each model. In addition, we report the Wald statistic for the joint significance of the instruments in the insurance participation equations. The results suggest a slight preference in favor of the second specification. Model 2 produces much bigger goodness of fit statistics. The Wald statistic is somewhat lower in this model but still highly significant.

Firm and job characteristics, which are assumed to be predictors of the likelihood of being offered insurance the yield similar effects in both models; and are highly 
significant. The coefficients exhibit a pattern to be expected with their interpretation as indicators of insurance offer. Thus union workers and employees in management or professional positions are more likely to have insurance compared with other employees. The negative coefficient of 'employed' indicates that employees in small firms (i.e. not of size category two or three) are less likely to have insurance than the unemployed. On the other hand employees in mid-sized and large firms are more likely to have insurance, with an effect that increases with the size category. These effects are to be expected given what is widely known about insurance offering by employers in general. In particular while most small firms do not offer insurance to their employees (Ginsburg and Gable, 1996) certain employed workers continue to access to insurance, either because they are on public assistance programs such as SSDI, or in cases of short run employment they may continue to carry their old insurance policy under ERISA. Firms that offer 401k plans are more likely to offer health benefits, leading to the positive coefficient of $401 \mathrm{k}$ in the regressions.

Regional variables were included to account for mandates of minimum benefits and premium regulation, which vary from state to state, but are known to exhibit regional patterns. The coefficients indicate that people who reside in the south and west region of the U.S, are less likely to have insurance than people in the northeast, while those who reside in the Midwest are less likely to be insured, all else being equal.

Since results on socioeconomic and demographic characteristics and health behaviors are incidental to our main research question, we present them only briefly. The coefficients indicate the likelihood of purchasing insurance increases significantly with age, adjusted household income level (i.e., income-to-needs quintiles) or education level. Black and Hispanics were less likely to have insurance, whereas married persons are 
more likely to have insurance. Hazard rates $(\lambda)$ generated from the probit model are included as independent variables in the health status regressions summarized in Table 4. The estimated coefficients of the hazard are denoted as ? te.

Second Stage Estimates: Health Status Equations

Model 1 and Model 2 in Table 3 represent second stage estimates of 'treatment effect' models, corresponding to first stage estimates of Model 1 and 2 from the previous table. With some minor rounding off, the two regressions on health status yield virtually identical results. Thus, the discussion below applies equally to both specifications.

Although generally health declines with age, the lack of significance of the age variable here is not surprising given the narrow range of ages in our sample. While there is considerable discussion of health care disparities in health, racial/ethnic origin does not have a significant effect in our setting, probably as a result of holding socioeconomic status and health behaviors constant elsewhere. On the other hand, females have significantly lower health compared with males. As expected, there is a positive association between education and health, with diminishing incremental gains from one level of education to another. This result is consistent with the Grossman investment model, which predicts that an individual's marginal efficiency in deploying medical care and other health inputs increases with the level of education. Increases in relative income operate in a similar way as increases in educational attainment. There is a positive association between income (relative to need) and health. Again the incremental gain of this effect diminishes as income level rises, and becomes negligible at the highest quintile.

Three groups of variables deal with risky health behaviors, namely smoking, drinking, and obesity. Past smokers and current smokers experienced significantly lower 
health compared with non-smokers. Moderate alcohol consumption had no significant adverse health effects, whereas heavy drinking did. On the other hand, obesity is a highly significant factor, with progressively decreasing health as body-mass quintiles move higher. The lagged health index, which indexes initial health stock has a significantly positive effect. The simple interpretation of this variable is that better health in the past leads to better health in the future. A further interpretation of this variable, based on rearranging the model to form a change equation, also suggests that it reflects the rate of depreciation of health stock. ${ }^{9}$

Since our main research question has to do with the consequences of the lack of insurance, all of the preceding effects, while interesting, are essentially viewed here merely as controls. Nevertheless, it is noteworthy that these effects conform with the broad literature and what is generally well known about determinants of health, further indicating the validity of the health index as a measure of overall healthiness. This increases our confidence in the main finding, namely that lack of insurance has a significant negative impact on health. Because a number of measurement issues arose, we defer to the summary of related results as presented in Table 4 and Table 5.

\section{Endogeneity of the insurance indicator:}

Table 4 provides a comparison of the three general types of econometric models: ordinary least squares, the IV estimator, and the treatment model. The treatment model was previously described, but the main coefficients are included here for expositional

\footnotetext{
${ }^{9}$ More explicitly, the complement of the lagged health coefficient, 1- $0.54=0.46$ is the rate of depreciation, yielding a cumulative average annual rate of 0.8 percent over the observed four-year interval. Converted to elasticity terms, a 10 percent increase in past health contributes to approximately 5.percent increase in health in the later period, all things being equal.
} 
convenience. The specification of the IV model is analogous to the treatment model. Thus the same set of exogenous variable is included in both types of model, and insurance non-participation is instrumented two ways, i.e., using the strict identification criterion (Model 1), with insurance offer variables only, and then using a fuller specification with the full vector of health status covariates (Model 2).

Only coefficients of the test variables and test scores, along with their levels of significance are included in Table 4. The most important set of results pertains to the insurance participation variable. The OLS model serves as a baseline case. As was suspected, OLS underestimates the true effect of having insurance on health. The IV and treatment models yield much larger estimates, but are similar to each other (Respectively, 4.06 and 5.05 in Model 1; 4.07 and 4.70 in Model 2).

The coefficients of the first-stage residuals in the IV model and the coefficients of $\lambda$ in the treatment models are negative, implying that OLS underestimates the effect of insurance. Since these coefficients are statistically significant in the first IV model and in both treatment models we reject the null hypotheses that the error terms in the two stages of the estimation are uncorrelated. However, estimates from IV estimators are always less efficient (Vella and Verbeek, 1999). Therefore we refer to the treatment model henceforth. Note that we made no a priori conjectures about the direction of the bias. The results suggest that the former is the dominant explanation. An alternative explanation is related to an unobservable trait, say a propensity to exhibit behaviors consistent with moral hazard. This would lead people to choose insurance while reducing preventive effort, and hence health status.

Although we obtain strong results about the need to correct for endogeneity bias, a question may arise regarding the quality of our instruments. The Wald-tests for 
parameter restrictions that we report in Table 2 indicate that our instruments are jointly significant. While it is impossible to test for the correlation between the instruments and potentially unobservable characteristics in the health equation, results from the indirect test are encouraging. We regressed the health index on the full set of variables, including all nine instruments from the first stage. We ran these regressions separately for the subsample of the uninsured, the subsample of the insured, as well as for the pooled sample. In all of these runs, none of the instrumental variables were significant at the 5\% significance level, save only the variable, 'employed', which designates workers who are self-employed or in small firm ${ }^{10}$. One of regional variables, West, was moderately significant (10\% level) only in the uninsured regression. The low regional variation in health in our sample may not apply to the population overall. While we cannot assert with certainty that these variables are uncorrelated with unobservable health status, the results from these additional regressions ${ }^{11}$ are strongly suggestive of this, at least for the particular population in our data.

To put the magnitude of the insurance participation effect in perspective we calculated the average treatment effects and population effects on health due to providing insurance to the previously uninsured, and expressed them in percentage terms. Using OLS and ignoring endogeneity, these are $2.0 \%$ and $0.3 \%$. Accounting for endogeneity, the effects on health are $7.2 \%$ and $1.3 \%$ respectively. Thus correcting for the bias provides more favorable support in favor of extending insurance coverage to all.

\footnotetext{
${ }^{10}$ In trial regressions we took 'employed' out of the first stage, but found virtually no effect on the lambdas. Thus we report the original specification.

11 Side regressions are available from the authors upon request.
} 


\section{Results: Chronic Conditions.}

One question that arises is whether health insurance matters more when some medical conditions are present, but not others. When recognizable symptoms appear, i.e., a medical condition is symptomatic, an individual may seek treatment regardless of insurance coverage to relieve pain and suffering. Certain chronic conditions, such as diabetes and hypertension are often asymptomatic; the demand for health care services by an individual with an asymptomatic condition may be more sensitive to out of pocket payments. Thus, we hypothesized that lack of health insurance has a greater adverse effect on health (through greater negative effects on health care use) for individuals with asymptomatic conditions compared to individuals with symptomatic conditions.

To allow for differential effects we replicated the previous analysis for major groupings of chronic conditions available in the Health and Retirement Study. Table 4 presents regression results for no chronic condition, all major chronic conditions (mainly cancer, stroke, heart disease asthma, other upper respiratory illnesses ${ }^{12}$ the subset of 'asymptomatic' conditions, i.e. diabetes and hypertension, and for hypertension only. ${ }^{13}$ We do not report results for the subgroup of symptomatic conditions, since the small sample size $(n=2,042)$ resulted in a poor statistical fit. We did not perform separate regressions on other individual diagnoses such as cancer or stroke due to small sample sizes.

${ }^{12}$ Respiratory illnesses include chronic obstructive pulmonary disease (COPD) or emphysema. Cancer may be diagnosed prior to appearance of symptoms, but is classified is a symptomatic disease because symptoms would typically appear a short time later.

${ }^{13}$ Another common asymptomatic condition, high cholesterol count, was not available from the survey. 
To conserve space and avoid redundancy, first stage insurance participation regressions are not presented, as all versions were similar to those for the pooled model previously discussed (Table 2). Thus we present only the second-stage health status models. Coefficients of risk behavior variables display the familiar pattern whereby excessive drinking, smoking, and obesity impact negatively on health. It is striking how these effects persist with similar magnitudes for all subgroups. Having a chronic condition does not make these effects "worse", and not having a chronic condition does not make these effects less pronounced. Effects are somewhat less significant in the asymptomatic and hypertension groups, probably due to the smaller sample size. Other persistent effects that are noteworthy are as follows: education is associated with better health outcomes; females exhibit slightly lowered health values.

Coefficient of variables of main interest are summarized in Table 6 , including a comparison of OLS and the treatment effects model for each population. The coefficient of insurance participation, which is of greatest interest, is always higher in the treatment model. In this sense results for the subgroups are consistent with the results for the pooled sample. Moreover, these coefficients change from being non-significant in the OLS models (populations 2-4), to being significant at the 10 percent level in the treatment models. The magnitude of the adjusted effect is about the same in all populations. However, because the coefficient of lambda $\left(\mathrm{s}_{\mathrm{ts}}\right)$ is non-significant in these models, we cannot reject the null hypotheses that the error terms in the two stages of the estimation are uncorrelated. By extension we cannot reject OLS unambiguously, although the low standard error on the coefficient of the hazard may be due to smaller sample size. 
Another reason for treating the results with caution is the possibility of errors in self

reported diagnoses. ${ }^{14}$. From inspection of the regression results it is evident the insurance effects are of similar magnitudes in all of the sub-samples. While we cannot be sure that we captured relative effects precisely, the results are at least suggestive of there being no significant differences by type of chronic condition.

\section{Conclusions}

Previous studies that examined the effect of insurance participation on measures of health have found only small effects. For the most part, these studies did not explicitly address the issue of endogeneity bias that arises if the decision to purchase insurance is correlated with unobservable traits that may also impact future health. This study indicates that adjusting for endogeneity of insurance in health equations in a treatment effects or instrumental variable model leads to substantially larger insurance effects compared with a more naïve model. It is encouraging that this finding is consistent with that of Goldman et al., (2001), even though they examine the endogeneity issue in the context of a more specific population, that of AIDS patients, and for a different outcome, namely mortality.

\footnotetext{
${ }^{14}$ Underreporting of true medical conditions (i.e., false negative, or Type II errors) may also occur in symptomatic conditions, although to a lesser extent than in symptomatic conditions. In an interesting and comprehensive study, Baker, Stabile, and Deri (2001) suggest that false positive errors may also be high. Using Canadian data they rely on a comparison of self reported diagnoses with entries made by physicians in administrative medical records in a prior two-year window. However, the health services research and epidemiological literature caution against using administrative medical data as a benchmark, which may be even more prone to error since diagnoses are often coded only if relevant to billing. This literature suggests a higher degree of specificity in self-reported measures even compared with administrative data complied over long period (e.g., Vargas et al., 1993, Bowlin et al. 1997). It is not our intension here to side with either of these approaches, but rather to suggest that results should be treated with caution.
} 
The possibility that insurance effects may have been underestimated in the past suggests certain important policy implications. The rising number of the uninsured has lead to many proposals to expand options for private insurance coverage. While our results do not bear on the efficacy of one policy proposal versus another, they contribute to the general debate by showing that insurance participation indeed can result in better health, or conversely, that lack of access to health insurance may lead to adverse health outcomes. We found that on average, providing insurance to the previously uninsured results in a 7 to 8 percent improvement in overall health. The fact that our sample consists of working age adults, who are in the pre-Medicare stage of their lives, i.e. ages 45-64 suggests that one should also weigh the externalities in terms of potential savings to the Medicare program from earlier and more effective treatment that would be come available for the uninsured. Ultimately policy choices for expanding coverage would depend on programmatic costs of expanding coverage, in addition to benefits, but our results still make the case for expanded coverage more attractive. It should be noted that the Health and Retirement Study does not contain information on the type of plan or the generosity of benefits available respondents. This issue should be examined in future research. 


\section{References}

Acs, G., SH. Long, S. Marquis, and P. Farely-Short. 1996. "Self Insured Health Plans:

Prevalence, Profile, Provisions and Premiums.” Health Affairs 15(2):267-278.

Averett S. and S. Korenman. 1996. “The Economic Reality of the 'Beauty Myth': Economic Differentials by Body Mass, Journal of Human Resources 31: 2.

Ayanian JZ, Kohler BA, Abe T, Epstein AM. 1993. "The Relation Between Health Insurance Coverage and Clinical Outcomes Among Women with Breast Cancer." New England Journal of Medicine 329(5):326-331.

Baker, M., M. Stabile, and C. Deri. 2001. What Do Self-Reported, Objective, Measures of Health Measure Tell? NBER Working Paper 8419.

Baker, David W., Joseph J. Sudano, Jeffrey M. Albert, Elaine A. Borawski, and A. Dor. 2001. "Lack of Insurance and the Risk of a Decline in Self Reported Health and Physical Functioning in Older Adults." New England Journal of Medicine 345(15):1106-12.

Bowlin SJ, Morrill BD, Nafziger AN, Jenkins PL, Lewis C, Pearson TA. 1993. "Validity of Cardiovascular Disease Risk Factors Assessed by Telephone Survey: the Behavioral Risk Factor Survey. Journal of Clinical Epidemiology 6(6):561-71.

Clark DO, Stump TE, Wolinsky FD. 1998. "Predictors of Onset of and Recovery from Mobility Difficulty Among Adults Aged 51-61 Years.” American Journal of Epidemiology 148(1):63-71.

Blendon, Robert J., John T. Young, and Catherine M. DesRoches. 1999. "The Uninsured, the Working Uninsured, and the Public.” DataWatch. Health Affairs 18(6):203-211.

Bundorf, Kate M. 2002. "Employee Demand for Health Insurance and Employer Health Plan Choices." Journal of Health Economics 21(1):65-88.

Chernew, M, K. Frick and KC McLaughlin. 1997. "The Demand for Health Insurance by Low Income Workers: Can Reduced Premiums Achieve Full Coverage?" Health Services Research 32(4): 453-470.

Custer, WS, and P. Ketsche. 2000. "Health Insurance Coverage and the Uninsured: 1990-1998." Health Insurance Association of America, Washington DC.

Cutler, D.M. 1994. "A Guide to Health Care Reform.” The Journal of Economic Perspectives 8(3): 13-29.

Gleckman, H. 2002. "Who Should Get the Health-Care Bill? Bush's Tax-Credit Plan is Fueling a Big Dispute in Washington.” BusinessWeek, March 4, 2002.

Goldman DP, J. Bhattacharya, DF McCaffrey, N. Duan, AA Leibowitz, GF Joyce, SC Morton, 2001. "Effects of Insurance on Mortality in an HIV-Positive Population In Care." Journal of the American Statistical Association 96(445): 883-893

Gruber, J. 2000. “Medicaid”. NBER Working Paper 7829. 
Gruber, J. 2001. Taxes and Health Insurance. NBER working paper 8657.

Frank CW, Weinblatt E, Shapiro S, Sager RV. 1966. "Myocardial Infarction in Men: Role of Physical Activity and Smoking in Incidence and Mortality. JAMA 198(12):1241-5

Franks P, CM Clancy, MR Gold. 1993. "Health Insurance and Mortality: Evidence from a National Cohort." JAMA 270(6):737-741.

Fillenbaum GG, Burchett BM, Welsh KA. 1993. "The 20-Item Word List Test as a Measure of Cognitive Functioning in the Health and Retirement Survey: Norms and Validity for White, African-American, and Hispanic Respondents.” Ann Arbor, MI: University of Michigan. 94005: Health and Retirement Study Working Paper Series.

Fuchs, VR. 2001. The Financial Problems of the Elderly: A Holistic Approach. NBER Working Paper 8236.

Ginsburg, PB, Gabel JR, Hunt KA. 1997. “Tracking Small-Firm Coverage, 1989-1996.” Health Affairs 17(1).

Goldman DP, J. Bhattacharya, DF McCaffrey, N. Duan, AA Leibowitz, GF Joyce, SC Morton. 2001. "Effects of Insurance on Mortality in an HIV-Positive Population In Care." Journal of the American Statistical Association 96(445): 883-893

Grossman, M. 1972. The Demand for Health: A Theoretical and Empirical Investigation. NBER Occasional Paper 119.

Grossman, M. 1972. "On the Concept of Health Capital and the Demand for Health." Journal of Political Economy, 80(2): 223-255.

Heckman, J. J. 1978. "Dummy Endogenous Variables in a Simultaneous Equations System." Econometrica 46(4): 931-960.

Heckman, J. J. 1979. "Sample Selection Bias as a Specification Error.” Econometrica 47(1):153161.

Hurd, M.D. , K. McGarry. 1995. "Evaluation of the Subjective Probabilities of Survival in the Health and Retirement Study. Journal of Human Resources 30(supplement): 268-291.

Jaeger, DA., Bound J, and RM Baker. June 1995. "Problems with Instrumental Variables Estimation When the Correlation Between the Instruments and the Endogenous Explanatory Variable is Weak." Journal of the American Statistical Association 90(430): 443-450.

Kaestner, R., T. Joyce, and A. Racine. 1999. "Does Publicly Provided Health Insurance Improve the Health of Low-Income Children in the United States?" NBER Working Paper No. 6887.

Kenkel, DS. 1991. "Health Behavior, Health Knowledge, and Schooling." Journal of Political Economy 99(2): 287-305.

LaCroix AZ, Lang J, Scherr P, Wallace RB, Cornoni-Huntley J, Berkman L, Curb JD, Evans D, Hennekens CH. 1991. "Smoking and Mortality Among Older Men and Women in Three Communities." New England Journal of Medicine 6; 324(23):1619-25. 
Maddala, G.S. 1983. Limited-dependent and Qualitative Variables in Econometrics. New York: Cambridge University Press.

McBride, T. 1997. "Uninsured Spells of the Poor: Prevalence and Duration." Health Care Financing Review 17(1).

Mirowsky, J., and CE Ross. 1998. "Education, Personal Control, Lifestyle and Health: A Human Capital Hypothesis.” Research on Aging 20(4): 415-449.

Perry, CW, and HS Rosen. 2001. "The Self-Employed Are Less Likely To Have Health Insurance Than Wage Earners. So What?” NBER Working Paper 8316.

Sorlie PD, Johnson NJ, Backlund E, Bradham DD. 1994. "Mortality in the Uninsured Compared with That in Persons with Public and Private Health Insurance." Archives of Internal Medicine 154(21): 2409-2416.

Staiger, D. and Stock JH. 1997. "Instrumental Variable Regression with Weak Instruments." Econometrica 65: 557-586.

Thun MJ, Peto R, Lopez AD, Monaco JH, Henley SJ, Heath CW Jr, Doll R. 1997. "Alcohol Consumption and Mortality among Middle-Aged and Elderly U.S. Adults. New England Journal of Medicine: 337(24):1705-14.

Vargas CM, Burt VL, Gillum RF, Pamuk ER. 1997. "Validity of Self-Reported Hypertension in the National Health and Nutrition Examination Survey III, 1988-1991." Preventive Medicine 26 (5 Pt 1):678-85.

Vella, F. 1993. "A Simple Estimator of Simultaneous Equation Models with Censored Endogeneous Regressors." International Economic Review 34: 441-457.

Vella, Francis, and Marno Verbeek. 1999. "Estimating and Interpreting Models with Endogeneous Treatment Effects." Journal of Business and Economic Statistics 17(6):473-478.

Ware, JE, and CD Sherbourne Jr. 1992. "The MOS 36-Item Short-Form Health Survey (SF-36): I. Conceptual Framework and Item Selection.” Medical Care 305(6):473-483.

Ware JE, M Koincki, MS Bayliss, CA McHorney, WH Rogers, and A Raczek. 1995.

"Comparisons of Methods for the Scoring and Statistical Analysis of SF-36 Health Profile Survey: Reliability and Validity in a Patient Population.” Medical Care 33(4): AS264-79.

Winslow, R., and L. McGinley. 2001. "Back on the Front burner: Health Care is Once Again on the Legislative Agenda." The Wall Street Journal, February 21, 2001. 
Table 1. Variable definitions and descriptive statistics $(\mathrm{N}=9,050)$.

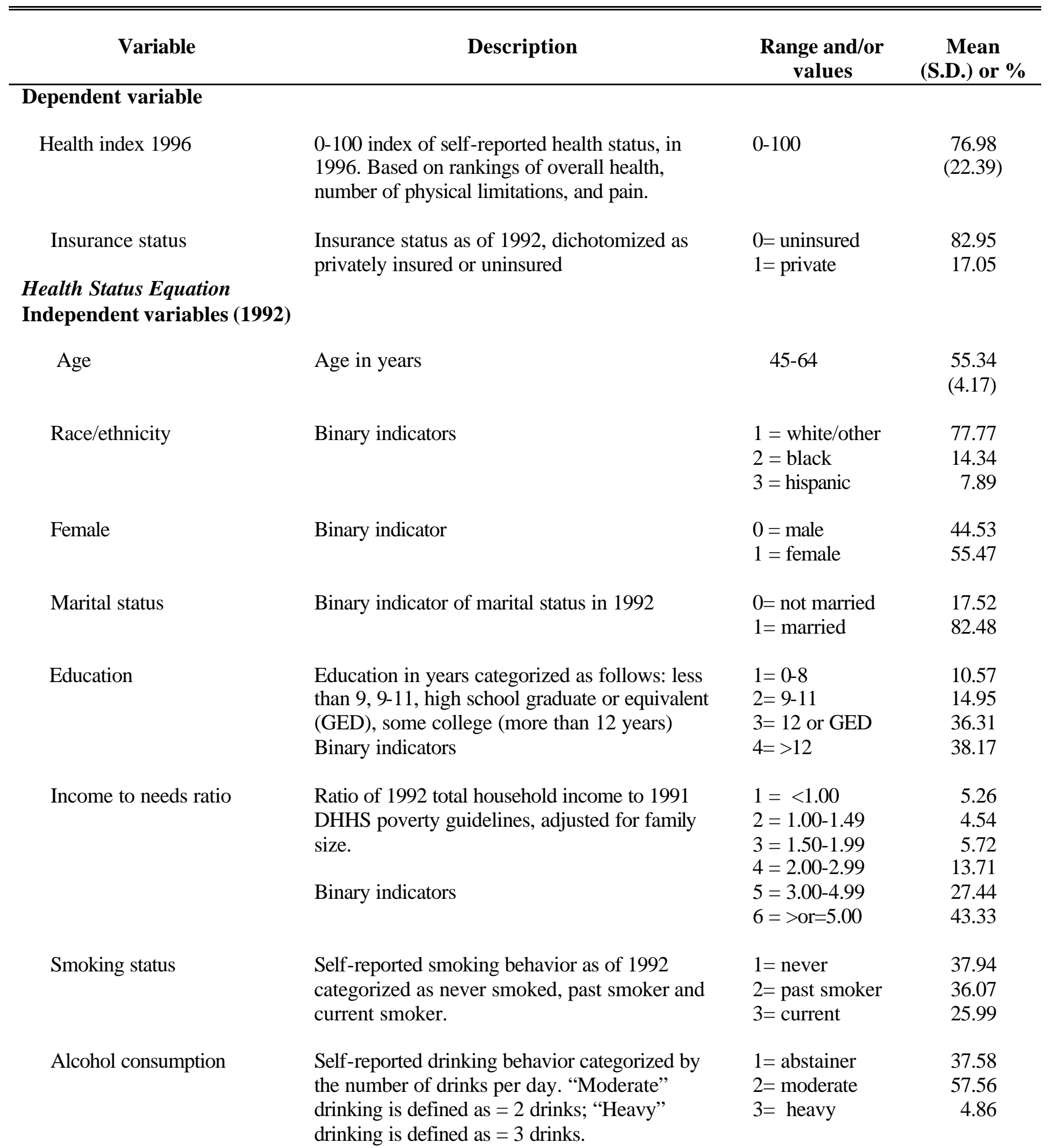


Body-mass index quintile

Health index 1992

\section{Participation equation: Additional independent variables (1992)}

Employed
Employer size 1
Employer size 2
Employer size 3
Occupation type.
Union
Pension Plan
Region

Body mass index (BMI) as of 1992 categorized by quintile. This the classic calculation of body weight for height, where $\mathrm{BMI}=\mathrm{kg} / \mathrm{m}^{2}$.

Binary indicators, quintile means reported.

Control variable for baseline health status in 1992
Quintile 1

Quintile 2

Quintile 3

Quintile 4

Quintile 5

$0-100$
21.15

24.18

26.37

75.84

(21.58)

Binary indicator

$0=$ unemployed

26.66

$1=$ employed

73.34

Dummy variable for employer size, base on

$0=$ all others

74.63

number of employees.

25.37

Dummy variable for employer size, base on

$1=<25$

78.84

number of employees.

21.16

$1=25-499$

73.10

$0=$ all others

26.90

number of employees.

$1=500+$

77.23

$0=$ all others

22.77

Status.

$1=$ prof $/$ manage

82.07

$0=$ non union

15.93

$0=$ not offered

39.43

Dummy variable for whether or not the

respondent has an offer for an employer

$1=$ offered

60.57

sponsored pension.

Geographic region of the United States

17.57

25.66

40.87

15.90 
Table 2: Probit Model for Insurance Choice (First Stage Estimates)

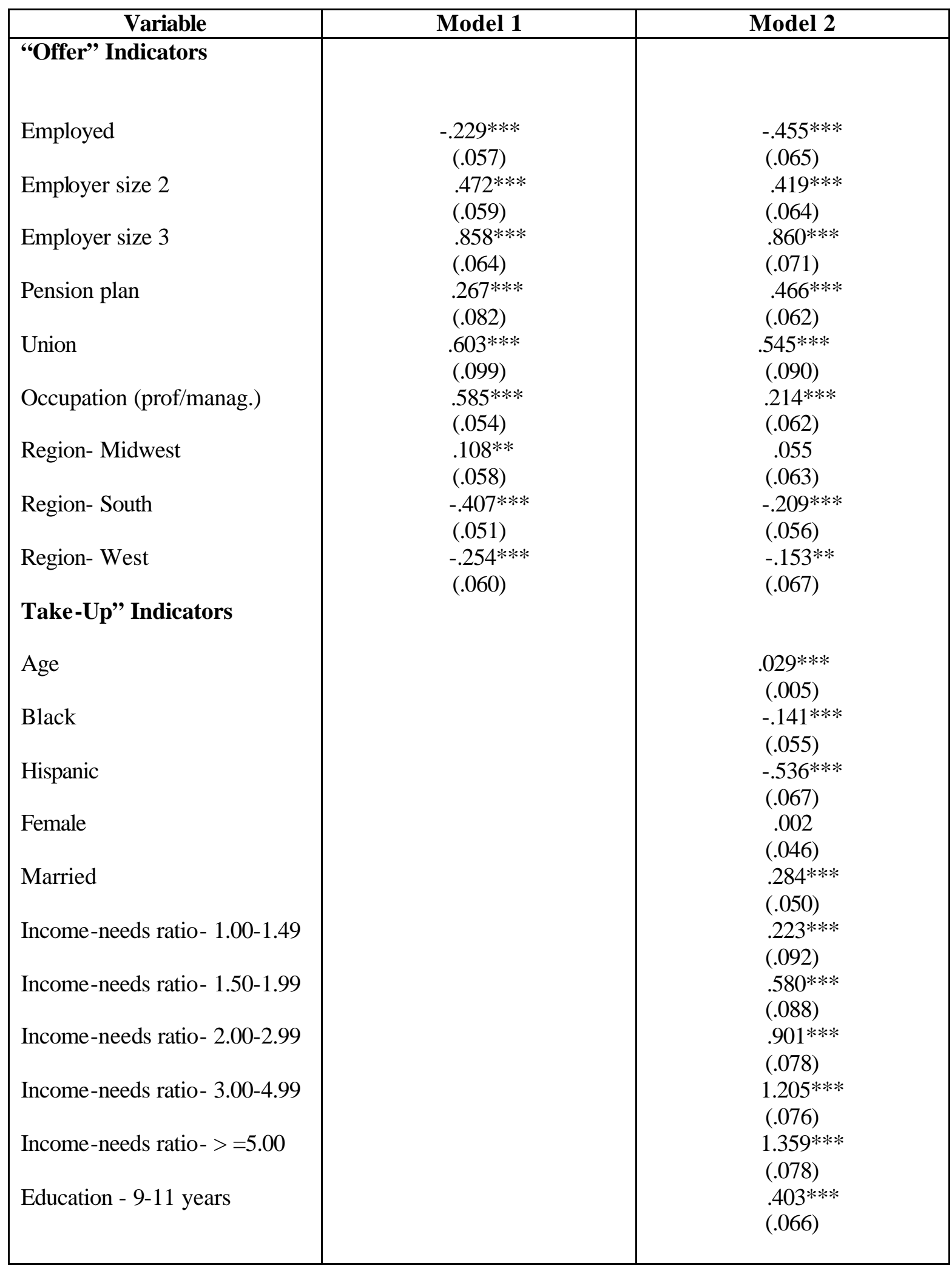


Table 2: Probit Model for Insurance Choice (First Stage Estimates) Cont'd

\begin{tabular}{|c|c|c|}
\hline Variable & Model 1 & Model 2 \\
\hline $\begin{array}{l}\text { Education - high school/GED } \\
\text { Education - college } \\
\text { Constant }\end{array}$ & & $\begin{array}{c}.555^{* * *} \\
(.062) \\
.577^{* * *} \\
(.067) \\
-2.356^{* * *} \\
(.312)\end{array}$ \\
\hline $\begin{array}{l}\text { Pseudo } \mathrm{R}^{2} \\
\text { Likelihood Ratio } \chi^{2}\end{array}$ & $\begin{array}{c}.1450 \\
1198.46\end{array}$ & $\begin{array}{c}.2971 \\
2456.04\end{array}$ \\
\hline $\begin{array}{l}\text { Wald-test on joint significance } \\
\text { of instruments (d.f. }=9) \\
\text { d.f. } \\
\chi^{2} \\
\text { p-value }\end{array}$ & $\begin{array}{c} \\
9 \\
991.46 \\
<0.001\end{array}$ & $\begin{array}{c}9 \\
888.92 \\
<0.001\end{array}$ \\
\hline $\mathrm{N}$ & 9,050 & 9,050 \\
\hline
\end{tabular}


Table 3: Health Status Equations

\begin{tabular}{|c|c|c|}
\hline Variable & Model 1 & Model 2 \\
\hline 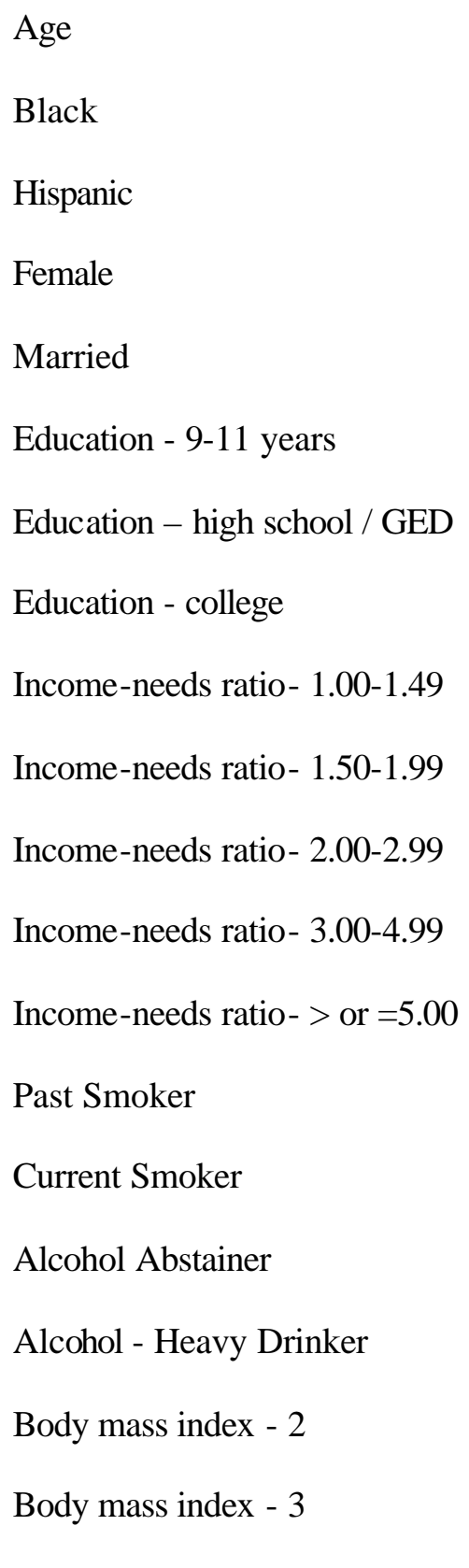 & $\begin{array}{l}-.032 \\
(.042) \\
-.454 \\
(.504) \\
.494 \\
(.686) \\
-1.441^{* * *} \\
(.377) \\
1.080^{* *} \\
(.471) \\
1.348^{*} \\
(.709) \\
3.412^{* * *} \\
(.658) \\
4.576^{* * *} \\
(.682) \\
.833 \\
(1.076) \\
.841 \\
(1.026) \\
.763 \\
(.893) \\
1.873 * * \\
(.862) \\
2.112^{* *} \\
(.878) \\
-.940^{* *} \\
(.403) \\
-3.269 * * * \\
(.446) \\
-.441 \\
(.371) \\
-1.601 * * \\
(.806) \\
-1.242^{* * *} \\
(.537) \\
-2.286^{* * *} \\
(.550) \\
\end{array}$ & $\begin{array}{c}-.057 \\
(.042) \\
-.356 \\
(.505) \\
.955 \\
(.719) \\
-1.502^{* * *} \\
(.378) \\
.801^{*} \\
(.470) \\
.928 \\
(.737) \\
2.897 * * * \\
(.705) \\
4.111^{* * *} \\
(.727) \\
.576 \\
(1.095) \\
.701 \\
(1.010) \\
.840 \\
(1.054) \\
1.571 \\
(1.092) \\
1.801 \\
(1.121) \\
-.975 * * \\
(.404) \\
-3.168 * * * \\
(.450) \\
-.477 \\
(.371) \\
-1.565 * \\
(.809) \\
-1.254 * * \\
(.539) \\
-2.252^{* * *} \\
(.551) \\
\end{array}$ \\
\hline
\end{tabular}


Table 3 (continued)

\begin{tabular}{|l|c|c|}
\hline \multicolumn{1}{|c|}{ Variable } & Model 1 & Model 2 \\
\hline Body mass index - & $-2.367^{* * * *}$ & $-2.330^{* * * *}$ \\
Body mass index - 5 & $(.549)$ & $.550)$ \\
& $-5.191^{* * *}$ & $-5.140^{* * *}$ \\
Health index 1992 & $(.566)$ & $(.567)$ \\
& $0.654^{* * *}$ & $.655^{* * *}$ \\
Insurance status & $(.009)$ & $(.008)$ \\
& $5.054 * * *$ & $4.702^{* * *}$ \\
Constant & $(1.356)$ & $(1.550)$ \\
& $23.662^{* * *}$ & $27.128^{* * *}$ \\
& $(3.004)$ & $(2.805)$ \\
& & \\
& & \\
& & \\
$?$ & & \\
$\mathbf{s}_{\mathbf{e}}$ & & -0.128 \\
$\mathbf{s}_{\text {te }}$ & & 15.969 \\
Wald $\left(\chi^{2}\right)$ & -0.144 & -2.043 \\
$\mathrm{~N}$ & 15.988 & 9943.46 \\
\hline
\end{tabular}

Note: $* \quad \geq 90 \%,<95 \%$ significance

$* * \quad \geq 95 \%,<99 \%$ significance

$* * * \quad \geq 99 \%$ significance 
Table 4. Instrumental Variable (IV) versus Treatment Model: Summary of Main Coefficients

\begin{tabular}{|c|c|c|c|c|c|}
\hline \multirow{2}{*}{ Variable } & \multirow[t]{2}{*}{ OLS } & \multicolumn{2}{|c|}{ IV Estimator } & \multicolumn{2}{|c|}{ Treatment Model } \\
\hline & & Model 1 & Model 2 & Model 1 & Model 2 \\
\hline $\begin{array}{l}\text { Lagged } \\
\text { Health }\end{array}$ & $\begin{array}{c}0.656 \\
(77.18)\end{array}$ & $\begin{array}{c}0.654 \\
(76.88)\end{array}$ & $\begin{array}{c}0.655 \\
(76.32)\end{array}$ & $\begin{array}{c}0.654 \\
(76.88)\end{array}$ & $\begin{array}{c}\mathbf{0 . 6 5 5} \\
(77.06)\end{array}$ \\
\hline $\begin{array}{l}\text { Insurance } \\
\text { Participation }\end{array}$ & $\begin{array}{l}1.373 \\
(2.27)\end{array}$ & $\begin{array}{l}4.068 \\
(2.08)\end{array}$ & $\begin{array}{l}4.067 \\
(2.08)\end{array}$ & $\begin{array}{l}5.054 \\
(3.73)\end{array}$ & $\begin{array}{l}4.702 \\
(3.03)\end{array}$ \\
\hline Residual & ----- & $\begin{array}{r}-4.492 \\
(-3.07)\end{array}$ & $\begin{array}{r}-3.111 \\
(-1.65)\end{array}$ & ----- & ----- \\
\hline$\lambda$ & ----- & ---- & ---- & $\begin{array}{l}-2.303 \\
(-2.93)\end{array}$ & $\begin{array}{l}-2.043 \\
(-2.27)\end{array}$ \\
\hline Adjusted $\mathbf{R}^{2}$ & 0.492 & 0.492 & 0.492 & ----- & ----- \\
\hline Wald $\chi^{2}$ & ---- & ---- & ---- & $\begin{array}{r}8631.9 \\
(\text { d.f. }=25)\end{array}$ & $\begin{array}{r}9943.5 \\
\text { (d.f. }=39)\end{array}$ \\
\hline
\end{tabular}

Notes: $t$ values in parentheses. 
Table 5: Treatment Effects Model by Type of Chronic Condition

\begin{tabular}{|c|c|c|c|c|}
\hline Variable & $\begin{array}{l}\text { No Chronic } \\
\text { Conditions }\end{array}$ & $\begin{array}{l}\text { All Chronic } \\
\text { Conditions }\end{array}$ & $\begin{array}{c}\text { Asymptomatic } \\
\text { Disease }\end{array}$ & Hypertension \\
\hline \multirow[t]{2}{*}{ Age } & -.055 & .010 & -.053 & -.033 \\
\hline & $(.059)$ & $(.057)$ & $(.074)$ & $(.078)$ \\
\hline \multirow[t]{2}{*}{ Black } & -.694 & .119 & .678 & .853 \\
\hline & $(.766)$ & $(.647)$ & $(.759)$ & $(.794)$ \\
\hline \multirow[t]{2}{*}{ Hispanic } & -.878 & 1.535 & 1.810 & $2.610^{*}$ \\
\hline & $(.919)$ & $(1.022)$ & $(1.274)$ & $(1.367)$ \\
\hline \multirow[t]{2}{*}{ Female } & $-1.057 * *$ & $-1.742 * * *$ & $-1.818^{* * *}$ & $-1.866^{* * *}$ \\
\hline & $(.516)$ & $(.509)$ & $(.645)$ & $(.677)$ \\
\hline \multirow[t]{2}{*}{ Married } & .791 & .599 & .340 & .740 \\
\hline & $(.677)$ & $(.620)$ & $(.779)$ & $(.814)$ \\
\hline \multirow[t]{2}{*}{ Education - 9-11 years } & $2.036^{*}$ & .627 & 1.293 & 1.245 \\
\hline & $(1.100)$ & $(.949)$ & $(1.177)$ & $(1.238)$ \\
\hline Education - high school / GED & $\begin{array}{l}2.697 * * * \\
(1.028)\end{array}$ & $\begin{array}{l}3.203 * * * \\
(916)\end{array}$ & $\begin{array}{l}4.306 * * * \\
(1.138)\end{array}$ & $\begin{array}{l}4.287 * * * \\
(1.202)\end{array}$ \\
\hline Education - college & $\begin{array}{l}4.060^{* * * *} \\
(1.055)\end{array}$ & $\begin{array}{l}4.500 * * * \\
(.946)\end{array}$ & $\begin{array}{l}5.593 * * * \\
(1.176)\end{array}$ & $\begin{array}{l}5.501 * * * \\
(1.238)\end{array}$ \\
\hline \multirow[t]{2}{*}{ Income-needs ratio- $1.00-1.49$} & 1.580 & $.042 * * *$ & -1.275 & -2.190 \\
\hline & $(1.737)$ & $(1.377)$ & $(1.724)$ & $(1.808)$ \\
\hline \multirow[t]{2}{*}{ Income-needs ratio- $1.50-1.99$} & -1.564 & .538 & .138 & -.865 \\
\hline & (1.687) & (1.406) & $(1.807)$ & $(1.893)$ \\
\hline \multirow[t]{2}{*}{ Income-needs ratio- $2.00-2.99$} & -.455 & -.860 & -1.317 & -2.163 \\
\hline & $(1.538)$ & $(1.392)$ & (1.784) & $(1.856)$ \\
\hline \multirow[t]{2}{*}{ Income-needs ratio- 3.00-4.99 } & .231 & .414 & -.699 & -1.862 \\
\hline & $(1.597)$ & (1.433) & $(1.832)$ & $(1.916)$ \\
\hline \multirow[t]{2}{*}{ Income-needs ratio- $>$ or $=5.00$} & -.335 & 1.132 & .270 & -.758 \\
\hline & (1.639) & $(1.465)$ & $(1.890)$ & $(1.983)$ \\
\hline \multirow[t]{2}{*}{ Past Smoker } & .188 & $-1.400 * * *$ & $-1.755^{* * * *}$ & $-1.714 * *$ \\
\hline & $(.563)$ & $(.541)$ & $(.680)$ & $(.710)$ \\
\hline \multirow[t]{2}{*}{ Current Smoker } & $-1.672 * * *$ & $-4.111 * * *$ & $-4.806 * * *$ & $-4.595 * * *$ \\
\hline & $\begin{array}{l}(.612) \\
.475\end{array}$ & $\begin{array}{l}(.608) \\
-.912 *\end{array}$ & $\begin{array}{l}(.790) \\
-1.472 * *\end{array}$ & $\begin{array}{l}(.834) \\
-1.331 * *\end{array}$ \\
\hline Alcohol Abstainer & $(.522)$ & $(.492)$ & $(.625)$ & $(.659)$ \\
\hline \multirow[t]{2}{*}{ Alcohol - Heavy Drinker } & -1.899 & -1.232 & -2.139 & $-2.481 *$ \\
\hline & (1.174) & $(1.056)$ & $(1.308)$ & $(1.347)$ \\
\hline \multirow[t]{2}{*}{ Body mass index - 2} & -.756 & $-1.339 *$ & -1.510 & -1.677 \\
\hline & $(.668)$ & $(.779)$ & $(1.130)$ & $(1.205)$ \\
\hline
\end{tabular}


Table 5 (continued)

\begin{tabular}{|l|c|c|c|c|}
\hline Variable & $\begin{array}{c}\text { No Chronic } \\
\text { Conditions }\end{array}$ & $\begin{array}{c}\text { All Chronic } \\
\text { Conditions }\end{array}$ & $\begin{array}{c}\text { Asymptomatic } \\
\text { Disease }\end{array}$ & Hypertension \\
\hline Body mass index - 3 & $-1.924^{* * *}$ & $-2.195^{* * *}$ & -.984 & -.782 \\
& $(.704)$ & $(.782)$ & $(1.105)$ & $(1.170)$ \\
Body mass index - 4 & $-1.524^{* *}$ & $-2.315^{* * *}$ & $-2.031^{*}$ & $-1.999^{*}$ \\
& $(.746)$ & $(.766)$ & $(1.073)$ & $(1.137)$ \\
Body mass index - 5 & $-3.328^{* * *}$ & $-5.197 * * *$ & $-5.093^{* * *}$ & $-4.854^{* * *}$ \\
& $(.846)$ & $(.764)$ & $(1.053)$ & $(1.118)$ \\
Health index 1992 & $.523^{* * *}$ & $.641^{* * *}$ & $.652^{* * *}$ & $.656^{* * *}$ \\
& $(.017)$ & $(.011)$ & $(.014)$ & $(.015)$ \\
Insurance status & $4.537^{* *}$ & $5.056^{* *}$ & $4.368^{*}$ & $4.629 *$ \\
& $(1.908)$ & $(2.119)$ & $(2.529)$ & $(2.611)$ \\
Constant & $39.496^{* * *}$ & $23.450^{* * *}$ & $26.892^{* * *}$ & $25.831^{* * *}$ \\
& $(4.097)$ & $(3.726)$ & $(4.781)$ & $(5.038)$ \\
& & & & \\
\hline$?$ & -.1050 & -0.1420 & -.1122 & -0.1435 \\
$\mathbf{S}_{\mathbf{e}}$ & 13.1355 & 17.1269 & 17.0810 & 17.1432 \\
$\mathbf{S}_{\text {te }}$ & -1.3787 & -2.4322 & -1.9163 & -2.4598 \\
$\mathbf{N}$ & $(1.1299)$ & $(1.2227)$ & $(1.4723)$ & $(1.5252)$ \\
\hline
\end{tabular}

\begin{tabular}{|c|c|c|}
\hline \multirow[t]{3}{*}{ Note: } & $*$ & $\geq 90 \%,<95 \%$ significance \\
\hline & $* *$ & $\geq 95 \%,<99 \%$ significance \\
\hline & $* * *$ & $\geq 99 \%$ significance \\
\hline
\end{tabular}


Table 6. OLS versus Treatment Models for Specific Chronic Disease Sub-populations.

OLS

Treatment Model

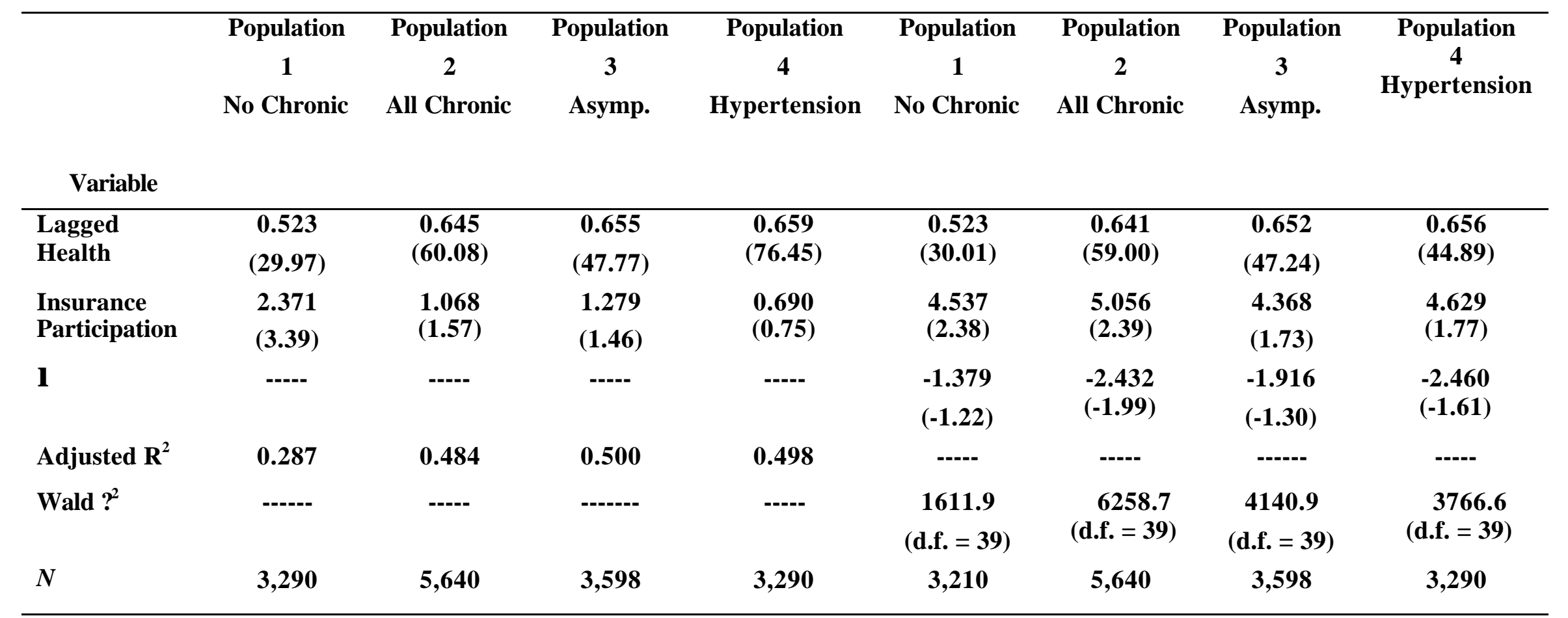

Notes: Population 1= persons with any of the following chronic diseases: hypertension, diabetes, chronic obstructive pulmonary disease (COPD) or asthma, heart disease, stroke, cancer, arthritis, visual difficulty. Population 2=persons with asymptomatic diseases: hypertension and diabetes. Population $3=$ persons with hypertension. 


\section{Appendix A: Moments of Health Index Distribution}

\begin{tabular}{|l|c|c|c|c|}
\hline & \multicolumn{3}{|c|}{ Health Status by Insurance Status and Survey Wave } \\
\hline & \multicolumn{2}{|c|}{ Uninsured } & \multicolumn{2}{c|}{ Insured } \\
\hline & Wave 1 & Wave 3 & Wave 1 & Wave 3 \\
\hline Mean & 68.7 & 69.05 & 77.3 & 78.6 \\
\hline St. dev & 25.46 & 25.7 & 20.39 & 21.28 \\
\hline Skewness & -.882 & -.827 & -1.33 & -1.39 \\
\hline Kurtosis & 2.85 & 2.61 & 4.53 & 4.41 \\
\hline
\end{tabular}

